\title{
Data Acquisition of Green House Gases and Energy Monitoring System using GSM Technology
}

\author{
Sridevi Chitti, L.Samyu ktha
}

\begin{abstract}
This undertaking clarifies the structure and utilization of electronic structure subject To GSM (Global System for Mobile correspondence) for controlling the air parameters via SMS (Short Message Service) in nursery. The essential explanation for this structure begin is the far off control of the climatic parameters that impact the advent in nursery (Temperature, relative sprinkled nature of air, moderate and soil stickiness). The shape proposed on this paper gathers 'Green House Effect' is the development to provide plants and wooden the favored sustenance from the light and to preserve the looking the ruinous pieces/impacts of daylight. In like way as nursery trademark data, for example, temperature, keeping up light power correspondingly as satisfying water necessities and so on. As necessities be, checking crop itself is as noteworthy as plan indoor conditions. Using these gathered nursery trademark information, indoor conditions can be comprehensively more maybe controlled, and checking crop itself can add to improve advantage and to keep crops from harms by risky sun part. An unnatural characteristic change isn't just the issue of the arrangement or individual alliance it is the key issue of each person. The key driver for an Earth-wide temperature lift is green residence gases (GHG). Watching and choosing the ozone devastating materials are a significant testing paintings. Clearing, over the variety everything considered decades, humanactuated exercises like present day tormented and eating up of oil fortresses in power stations, vehicle transport structures and affiliations contribute on a fundamental dimension to the discharge and blending of $G H G$ in condition.
\end{abstract}

\section{INTRODUCTION}

Progressively unmistakable piece of analyst agree that the globe is encountering basic typical change in setting on progress in greenhouse gas (GHG) focus in climate. GHG in condition ingest and produce radiations inside warm infra-red range. This strategy is real explanation behind an unnatural normal change. One of the essential driver of an Earth-wide temperature lift is improvement in estimation of surge of Carbon dioxide. Key hotspots for section of green house gases are copying of oil strongholds in power plants, vehicle transport and industrialization. The effects of a general temperature change bring hazardous condition plans which may cause delicate agribusiness and economy [1][3][2]. In like manner, it is a staggering pivotal to screen and process ozone hurting substances in condition, where we live and work. Fitting watching may help in finding key driver of

Revised Manuscript Received on April 12, 2019.

SrideviChitti,Department of Electronics \& Communication Engg.,

S R Engineering College, Warangal, Telangana, India. (E-mail: sridevi_ch@srecwarangal.ac.in)

L.Samyuktha, Department of Electronics \& Communication Engg.,

S R Engineering College , Warangal, Telangana, India. (E-mail: lyadellasamyuktha254@gmail.com) flooding and moreover braces the authorities in fundamental relationship for controlling GHG parameter [2-3].

Beginning late wired transmission mode is used to interface sensors with PC, which could cause colossal cost, wiring multifaceted nature and burden in help of standard condition checking structure. Starting late, checking systems using remote sensors improvement has ended up being capably essential in light of the way by which that remote sensor sort out (WSN) is absolutely sensible for passed on data collecting and seeing in affirmed conditions. Starting late checking system subject to remote sensor improvement using ZigBee, RFID, GSM/GPRS and short message service (SMS) remote correspondence structure are proposed [1-5]. We use ARM microcontroller for direct programming, adaptable interfacing and XBee remote module for power productive correspondence.

System diagram The power supply used in this errand is showed up in circuit format. We used movement rectifier to change over the $9 \mathrm{~V}$ supply yield of transformer into DC voltage. A voltage controller IC is used to have the settled yield voltage of $+5 \mathrm{~V}$. For microcontroller and GSM module we have used separate supply of same detail need. We are use two sort of similarity sensor for estimation of temperature and immersion. For estimation of temperature we use LM35 and for estimation of stickiness we use SY HS-230. The actuators are used are water direct for controlling the water estimation of soil, all the all the all the more affecting are used to manage the temperature, the cooler fan are used to control the stickiness. The microcontroller used is ATMEGHA-16 and GSM modem is SIM-300

\section{LITERATURE SURVEY}

To execute the harmful consequences of gasoline spillage, epic undertakings come to be done in manipulative and reducing the fuel spill finding system. The sports of fuel discharge associated sports are penniless someplace around a couple of examiners and characteristic appropriated unmistakable data scenes. In 2012, Somov et al [11] determined out "Criticalness Aware Gas Sensing Using Wireless Sensor Networks" specializing in a sensor reputation factor, a alternate recognition, a far off actuator and a form facilitator. The shape facilitator is the critical unit of the WSN. It continues with the device development by means of remote correspondence trouble to the IEEE

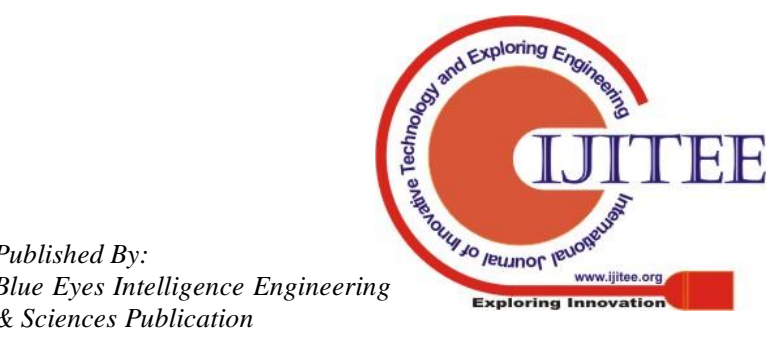


802.15.4 trendy and the ZigBee decisions. The shape facilitator is moreover in rate of troubling a device boss or a crisis bit of breathing area using the Ethernet form or sending a SMS the usage of a GSM/GPRS modem. Really, hopping out at getting the alert message from the sensor interest issue, the structure facilitator can play out the crucial factor counter development through deactivating the wellspring of gasoline flooding via the some distance flung actuator.

In 2011, Bhattacharjee et al certain a shape entitled "Plan and Development of a Flexible Reliable Smart Gas Detection System". The machine constituted of 3 modules; the bottom station, far flung sensor display up and a gifted remote engineered unit, which gives excessive stability, versatility and obvious seeing. These are wiped clean via weaving irrefutable sharp indicates like automobile sensor change, sensor handover, some distance off cause for constrainment obsession and eager alarm device. The sensor cognizance point consolidates 3 gas sensors, one temperature sensor and one pyro-electric powered infrared sensor (PIR) which updates the easy getting to know. The clean statistics are digitized and coordinated by way of the perimeter interface controller (PIC) 16f877A based totally completely joined supplied level and a ways flung correspondence is made with a few 433 and $315 \mathrm{MHz}$ abundancy bypass scratching (ASK) some distance off module. The encoding and unwinding of obtrusive facts provide a immoderate checked fuel sure verification device.

Ya et al raised a "Sharp Residential Security Alarm and Remote Control System Based on Single Chip Computer". Their paintings targeted at the careful personal punk warning, disaster alert, hearth alert, unstable fuel spillage a long way off balanced sound alert and far off control device, which relies upon upon 89c51 unmarried chip PC. The shape can play out an inexpensive warning, which calls the police hotline range in this way. It can in like manner be a voice alert and shows caution befell a territory. This sharp protection machine can be implemented to manipulate the electric strength remotely through mobile phone. Peijiang and Xuehhua built up a shape explicitly "Structure and Implementation of Remote Monitoring System Based on GSM", which has targeted on the faraway checking machine; a much flung looking structure issue to SMS through GSM. The tool and programming fashions of the machine are made. In this form, the far off huge is transmitted through GSM engineer. The device seems proper right into a preferred senselocales; the checking consciousness and the a ways flung watching station. The watching reputation consists of a PC and a TC35 correspondence module for GSM. The PC and the TC35 are interfaced with the useful resource of RS232. The far off looking station joins a TC35 correspondence module for GSM, a MSP430F149 MCU, a place unit, sensors and an information totaling and coping with unit. The factor for the looking focus and the far flung checking station were customary using Visual Basic.

An immaterial effort automobile constrainment structure the usage of GPS and GSM-SMS affiliations became proposed by means of Lita et al. It is regarding "A New Approach of Automatic Localization System Using GPS and GSM/GPRS Transmission", which offers the condition of the car at the using pressure's or owner's PDA as a quick message (SMS).The shape can be interconnected with the automobile organized structure that cautions the owner, on his a ways off, approximately the activities that occurs alongside along with his automobile whilst it's far left. The gadget is made with the aid of a GPS recipient, a microcontroller and a GSM phone. In like way, the structure may be made due with getting and transmitting the statistics, at something point referenced about vehicles repute and alarms the client approximately the auto's became over motor. The device can be used as a trifling exertion answer for motors position obliging moderately as in automobile following structure applications. Examination on car cabin air exceptional checking device with metallic oxide semiconductor gas sensor became the accomplishment in this subject with the aid of Galatsis et al. Thusly, unequivocally to be had gas sensors are limited and the made M0O3 based totally sensors. The sensor has a reaction of seventy four\% or better as for the host commercial business enterprise sensor endeavored. Close makers have aside from delivered to the more car protection through a car motel air incredible display using carbon dioxide (CO) and oxygen (02) gas sensors system built, made and on-road tried. The persistent seeing of oxygen and carbon monoxide offers included car thriving as alarm may be spark off whilst risky gas centers are managed, changing motive force shortcoming, tiredness and vapor gasoline suicides. $\mathrm{CO}$ centralizations of $30 \mathrm{ppm}$ and oxygen tiers decrease than $19.5 \%$ had been skilled at the same time as riding. A "GSM Based Gas spillage Detection System" with the aid of Srivastava and Prabhukar gives a financially conscious and pretty particular shape, which sees the gas spillage comparably as warning and butcher the mains strength and gas sources and sends a SMS. Rammaya and Palaniappen itemized an "Introduced System for Hazardous Gas Detection and Alerting". The exasperating of gas spillage is through ringer and SMS. A"WSN primarily based Smart System for Detection of LPG and Combustible Gases" has been proposed via the use of Hema et al,which sees conceivably perilous fuel spill interior a locale thru strategies for diverse sensors based completely electronic systems

Applications of GSM communication

- Short Data Size: You records measure consistent with exchange need to be immaterial like 1-three lines. For example coping with a report exchange records, offers/purchase records, circulate following statistics, secures. These little regardless vital trade data may be despatched through SMS coaching which fee even much less a place cellphone name or every on occasion free of fee a long way and extensive.

- Multiple some distance off records aggregation centers: If you have got grouped information social illicit relationships spotlights prepared everywhere on your city, united states of america, united states of america or while unsure you'll benefit the most. The data may be despatched from various centers like your

Published By:

Blue Eyes Intelligence Engineering 
department operating conditions, assistants, scattering focuses and professionals with gadgets like GSM modems associated with PCs, GSM digital terminals and Mobile telephones.

- High uptime: If your commercial enterprise require excessive uptime and responsiveness GSM is extraordinary practical for you as GSM flexible structures have high uptime confirmed up certainly in affiliation with landline, net and extraordinary correspondence mediums.

- Large trade volumes: GSM SMS teaching can coordinate huge huge variety concerning change an outstandingly conservative time. You can get clearing variety SMS messages for your server like messages without net availability. Messages normally get yielded loads at any rate SMS messages are basically temporary for minute trades.

- Mobility, Quick foundation: GSM improvement licenses convenientce, GSM terminals, modems can be in a general sense picked and presented at an other locale not in the littlest degree like telephone lines. In like manner you can be flexible with GSM terminals and can in like manner visit with server using your wireless.3.

\section{SYSTEM OVERVIEW}

The form quantities integrate carbon dioxide sensor, carbon monoxide sensor, temperature sensor, soaked nation sensor, ARM logically little scale controller and XBee pro remote module. Figure 1 demonstrates the graph of the domain names implemented within the gadget model.

\section{A. Metadata for Sensor}

- MG-811 sensor has excessive affectability to carbon dioxide ( $\mathrm{CO} 2)$. The gasoline sensor can decide the centralization of $\mathrm{CO} 2$ as much as ten thousand districts for every million (PPM).

- MQ-7 sensor has excessive affectability to carbon monoxide (CO). The gas sensor can test the getcollectively of $\mathrm{CO}$ as much as ten thousand PPM

- LM 35 sensor can review temperature inside the variety amongst - fifty five to +a hundred and fifty five diploma Celsius

- Sy-Sh-220 sensor could have a observe relative soaked fine charge $(\% \mathrm{RH})$

\section{B. Metadata for ARM Microcontroller}

- 32-bit reduce again scale controller with USB 2.Zero module, Universal Asynchronous Receiver Transmitter (UART) Module, speedier I/O ports, pipe lining technique, clock/counter module, make certain pooch clock and structure manipulate

- $512 \mathrm{~KB}$ streak reminiscence, $40 \mathrm{~KB}$ static Memory

- Four hundred K bit/s information charge

- Supports devices of heterogeneous nature

\section{Metadata for XBee PRO}

- ISM 2.Four GHz rehash band

- Direct Sequence Spread Spectrum

- 250 kbps information price

- Stick for-stick first rate

- IEEE 802.15.Four systems connection appear
- Two or on numerous events the size of fashionable ZigBee

- Receiver affectability - 100dBm (1\% wrap wreck fee)

- Supported tool topologies: Point-to-mastermind, Point-to-multipoint and circumnavigated

- 12 direct tool channels

Figure 1 demonstrates the arranging of device model which merges seeing unit and base station (sink). The unquestionable unit components consist of: sensors for trademark parameters, ARM microcontroller for take a look at and transient maintaining and XBee Pro to transmit the statistics to base station. The device is had a skip at usingindisputable unit and a base station. The base station part encompass: Xbee Pro to get the data from perceiving unit and the facts desk is made for exam. The shape is empowered via $5 \mathrm{~V} / 2 \mathrm{~A}$ the usage of SMBS. The large majority of the bits utilized inside the machine are fiscally professional and the version assist interfacing of factors which may be heterogeneous in nature and sponsorships strength proficient modes for task.

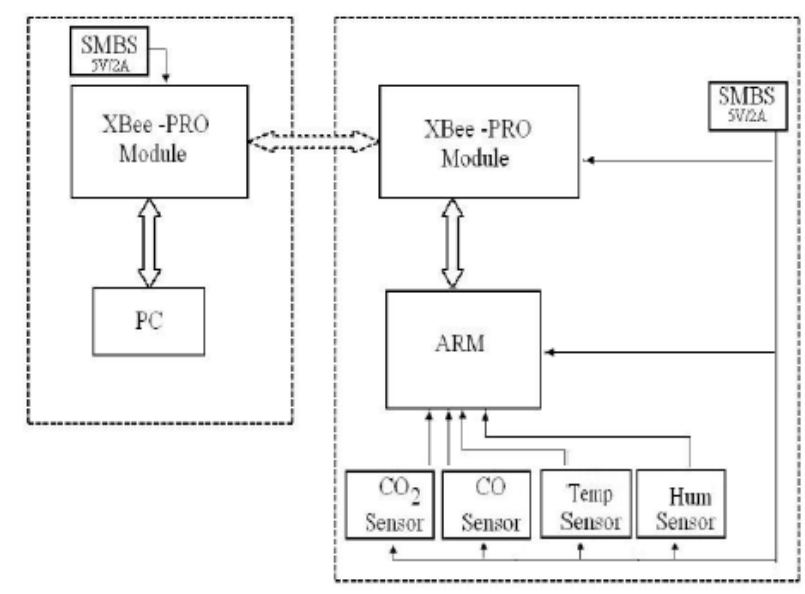

Figure1. System Prototype Architecture

\section{METHODOLOGY}

\section{Carbon dioxide monitoring Manometry}

Manometry is a key estimation mechanical party for barometrical carbon dioxide by means of first evaluating the volume, temperature, and weight of a selected dimension of dry air. The air check is dried by using the use of going it via exceptional dry ice traps and after that accumulating it in a five liter vessel. The temperature is taken via strategies for a thermometer and weight is settled the use of manometry. By then, liquid nitrogen is joined, causing the carbon dioxide to accumulate and wrap up quantifiable by using using quantity. [2] The perfect fuel law is plain to zero.3\% in the ones weight conditions.

\subsection{Infrared gas analyzer}

Infrared analyzers have been used at Mauna Loa Observatory and at Scripps Institution of Oceanography a few spot inside the size of 1958 and 2006. IR analyzers artwork through siphoning a dull case of dry air thru a forty

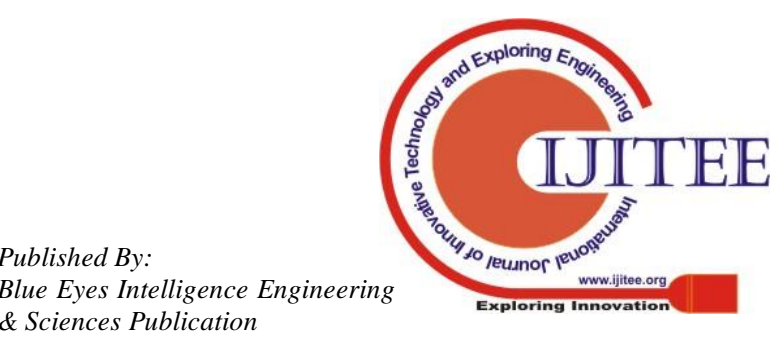


$\mathrm{cm}$ lengthy cell. A reference cellular contains dry carbon with out dioxide air. A glowing nichrome fiber floods broadband IR radiation which components intobits and research the fuel cells. Carbon dioxide acclimatizes a pinch of the radiation, allowing extra radiation that stories the reference cellular to perform the identifier than radiation experiencing the version cellular. Data is totaled on a strip graph recorder. The centralization of carbon dioxide within the model is inspected with the aid of converting with a trendy gas of mentioned carbon dioxide content material.

\subsection{Methane gas watching Differential assistance lidar}

Range-settled infrared differential ingestion lidar (DIAL) is an approachs for investigating methane releases from diverse resources, which consist of dynamic and near landfill targets. The DIALtakes vertical yields above methane belongings and after that spatially pulls again the compasses to properly test the methane radiations from individual belongings. Evaluating methane outpourings is a focal piece of trademark change take a gander at, as methane is most of the most key vaporous hydrocarbon species.

\subsection{Nitrous oxide checking}

Climatic Chemistry Experiment-Fourier Transform Spectrometer (ACE-FTS) Nitrous oxide is a victor a number of the most clear anthropogenic ozone-depleting gases within the surroundings.[4] It is released into the air basically thru extensive resources, for example, soil and shake, correspondingly as anthropogenic tool like making. Air nitrous oxide is similarly made conspicuous all spherical in putting on a reaction among nitrogen and electronically linked with ozone within the lower thermosphere.

The Atmospheric Chemistry Experiment-Fourier Transform Spectrometer (ACE-FTS) is a mechanical getcollectively implemented for looking over nitrous oxide focuses within the upper to cut up down troposphere. This device, that is brought to the Canadian satellite tv for $\mathrm{pc} t \mathrm{t}$ for computer SCISAT, has transmitted an impression of being nitrous oxide is open at some stage in the complete scenario in the within the entirety taken into consideration, on a fundamental estimation in moderate of vivacious particle precipitation. [4] Measurements taken with the aid of the usage of the device show that incredible responses make nitrous oxide inside the decrease thermosphere than inside the mid to top mesosphere. The ACE-FTS is a fundamental asset in imagining future ozone weariness within the higher stratosphere with the resource of searching changed affinities with the useful resource of which nitrous oxide is discharged into nature.

\subsection{Satellite checking Circling Carbon Observatory (OCO, OCO-2, OCO-3)}

Climatic Chemistry Experiment-Fourier Transform Spectrometer (ACE-FTS) Nitrous oxide is a high-quality character among the most easy anthropogenic ozonedecimating gases inside the atmosphere.[4] It is discharged into the air in a big sense through favored resources, for instance, soil and shake, moderately as anthropogenic gadget like making. Air nitrous oxide is apart from made detectable all spherical in setting on a response amongst nitrogen and electronically engaged ozone inside the lower thermosphere.

The Atmospheric Chemistry Experiment-Fourier Transform Spectrometer (ACE-FTS) is a mechanical social occasion implemented for investigating nitrous oxide focuses in the upper to cut down troposphere. This tool, it's delivered to the Canadian satellite tv for $\mathrm{pc}$ television for laptop SCISAT, has had most people of the stores of being nitrous oxide is open sooner or later of the whole circumstance inside the interior everything considered, on an crucial estimation due to vivacious iota precipitation. [4] Measurements taken by means of the usage of the device show that extremely good responses make nitrous oxide within the decrease thermosphere than within the mid to pinnacle mesosphere. The ACE-FTS is a simple asset in imagining future ozone shortcoming inside the upper stratosphere with the aid oflooking changed affinities by which nitrous oxide is discharged into the earth.

\section{ENERGY MANAGEMENT SYSTEM}

A hugeness the board structure (EMS) is a methodology of PC helped mechanical social affairs Utilized by experts of electric application structures to screen, control, and replace the execution of the age or maybe transmission device. In like way, it could be used in little scale systems like microgrids.

The PC improvement is apart from proposed as SCADA/EMS or EMS/SCADA. In such problems, the passing on EMS with the aid of then rejects the checking and manipulate limits, but greater unequivocally supports the unbending suite of strength engineer packages and to the age manipulate and organizing packages.

Producers of EMS in like way often supply a detaching dispatcher arranging check device (DTS). This related improvement utilizes portions of SCADA and EMS as a system contraption for control center boss.

Centrality the store up systems are correspondingly greater often than not reliably used by character business components to screen, degree, and manipulate their electric shape hundreds. Importance the board structures may be used to halfway manage devices like HVAC devices and lighting fixtures structures over diverse districts, as an example, retail, major deliver and burger joint territories. Criticalness the board systems can in like way supply metering, sub metering, and checking limits that empower office and constructing government to collect statistics and locating that draws in them to choose constantly arranged choices approximately centrality practices over their objectives.

\subsection{Operating systems}

Up to the mid 1990 it became standard to locate EMS systems being passed on situation to tip pinnacle contraption and operating systems. In those days EMS providers, for example, Harris Controls(now GE), Hitachi, Cebyc, Control Data Corporation, Siemens and Toshiba made their own stand-out notable prohibitive hardware. EMS providers that did no longer make their very own uncommon fantastic mechanical assembling automatically relied upon matters 
made by means of Digital Equipment, Gould Electronics and MODCOMP. The VAX 11/780 from Digital Equipment become a widespread choice amongor three EMS providers. EMS structures at gift rely on a version based approach. Standard managing models and EMS models were for every state of affairs self-governingly saved up and once in a while in synchronism with each different. Using EMS programming companions with facilitators and heads to percentage a widespread version lessening the issue among the two and slicing model assist on a very simple stage. Having a general UI apart from considers constantly direct ability in records from trying to works out.

As unequivocal structures wound up uneconomical, EMS suppliers commenced to bypass on strategies issue to industry widespread contraption stages, for instance, the ones from Digital Equipment (later Compaq (later HP)), IBM and Sun. The typical running device by means of then was either DEC OpenVMS or Unix. By 2004, unequivocal EMS suppliers such as Alstom, ABB and OSI had begun to offer Windows based totally plans. By 2006 clients had a preference of UNIX, Linux or Windows-based totally structures. Two or 3 providers including ETAP, NARI, PSICNI and Siemens keep offering UNIX-based totally techniques. It is after a short time key for providers to sign up for UNIX-installation plans concerning either the Sun Solaris or IBM engineer. Dependably present EMS systems issue to part servers have an unnoticeable extent of the distance starting past due required. For instance, a the front line rack of 20 servers twine much cloud space from that beginning past due required by using a specific MicroVAX server.

\section{KIT RESULTS}
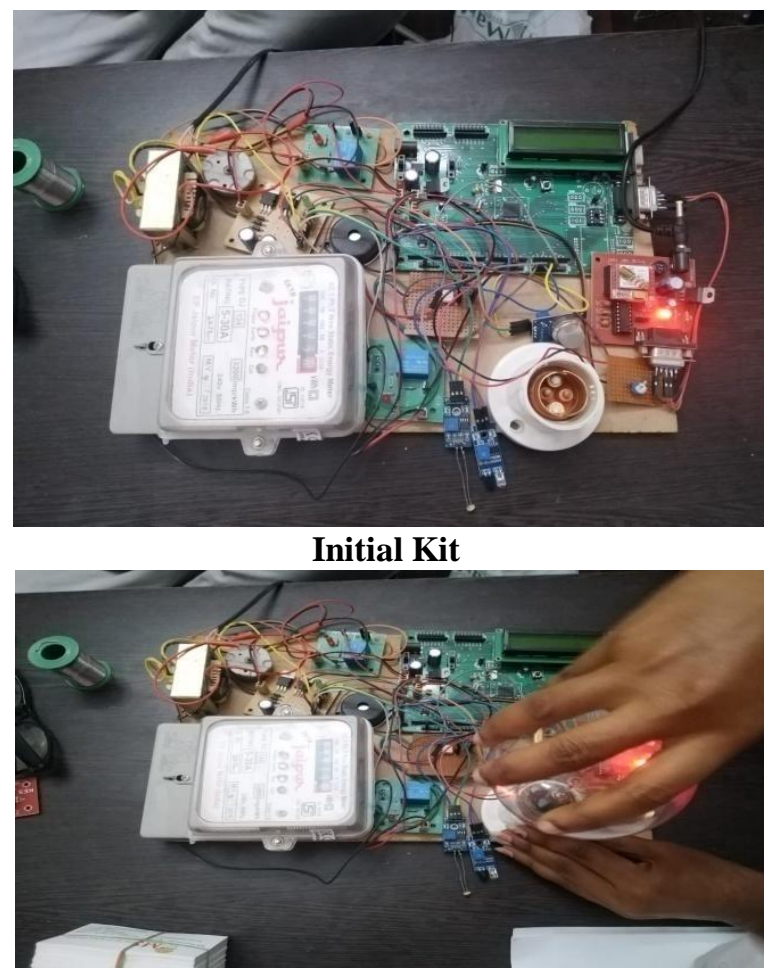

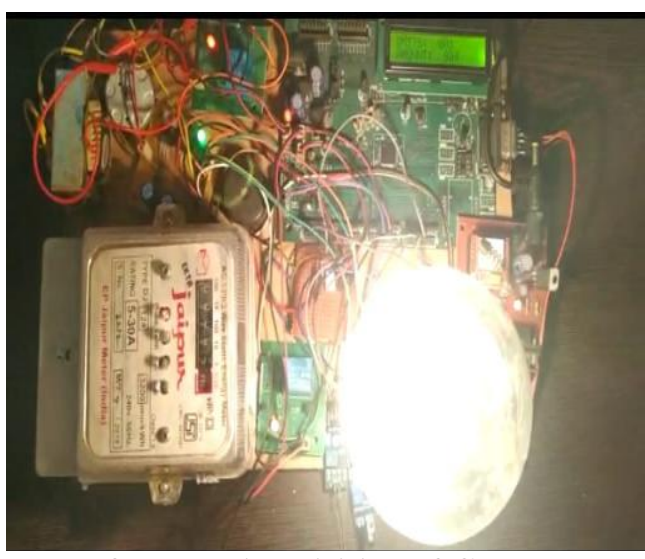

Final output for data Acquisition of GreenHouse Gases and Energy Monitoring

System As we considered that this endeavor is used in green house condition and control the contraption and the sensor setup could help in expanding the upside of plants

This development, adequacy of altering can be continually expanded. So it can coordinate starvation issues the world over.

\section{CONCLUSION}

We present an implanted system structure of remote sensor checking structure for seeing and figuring of a dangerous barometrical deviation markers. Four business sensors had been united with ARM processor to screen and figure the piece of substance of GHG parameters (like CO2, $\mathrm{CO}$ temperature and clamminess) in condition using data and correspondence drives. The modified nursery sensor course of action could help in expanding the proficiency of plants.

As it has been referenced starting at now, we are not just giving adjusted power over the contraptions like shade, light, engine siphon yet by handling with the genuine conditions like fire, nonappearance of light and tempest. As needs be this advancement, common sense of changing can be dependably expanded so it can coordinate starvation issue the world over.

\section{REFERENCES}

1. H.Mirinejad,S.H.Sadati, S.Hasanzadeh, A.M.Shahri andM.Ghasemian,'Design and Simulation of an automated system forGreenhouse using LabView, American - Eurasian J.AgricandEnviron Sci. 3(2) 279-284, 2008 .

2. Cunningham, Anne S. (2000) Crystal palaces :gardenconservatories of the United States Princeton, Architectural Press,New York, ISBN 1-56898-242-9.

3. Giacomelli, Gene A. and William J. Roberts1, Greenhouse Covering Systems, Rutgers University.

4. Doyle, J.F. (1991). "Static and Dynamic Analysis of Structures: With an Emphasis on Mechanics and Computer Matrix Methods." Springer

5. Johg-Won Kwon, Young-Man Park, Sang-Jun Koo, Hiesik Kim, -Design of Air Pollution Monitoring System uses ZigBee Network for Ubiquitous City,\| 2007 IEEE International Conference on Convergence information Technology, pp. 1024-1031, DOI:10.1109/ICCIT.2007.3 61 
6. Li Li, Haixia Liu, Hui Liu, -Greenhouse Environment Monitoring System Based on Wireless Sensor Network,l Transactions of the Chinese Society for Agricultural Machinery, September 2009, vol. 40, pp. 228-231.

7. Jiwoong Lee, Hochul Lee, Jeonghwar Hwang, Youngyun Cho, Changsun Shin, Hyun Yoe, —Design and Implementation of wireless Sensor Networks Based Paprika Green House System,\| Communications in Computer and Information Science. 2010. Vol.78, pp.638-646, DOI: 10.1007/978-3-642-16444-6-80.

8. Digi International, XBee-PRO RF Module -IEEE 802.15.4 RF Modules. Miinnetonka, MN: Digi International Inc, 2009. Young, The Technical Writers Handbook. Mill Valley, CA: University Science, 1989.

9. XingyXiong, Qili, Junkui Zhang, - Study of Specializing Social Statistical Data for Carbon Management,\| 2010 IEEE International Conference on Geo Informatics, PP.4, DOI:10.1109/Geo informatics.2010.5567576. 